\title{
Atividade antimicrobiana de derivados fenólicos do líquen Ramalina sorediosa (B. de Lesd.) Laundron ${ }^{1}$
}

\author{
Emerson P. da Silva Falcão ${ }^{1,2}$, Nicácio H. da Silva ${ }^{3}$, Norma B. Gusmão², \\ Sheyla Mara Ribeiro ${ }^{3}$ e Eugênia C. Pereira ${ }^{3,4}$
}

Recebido em 06/05/2003. Aceito em 02/06/2004

\begin{abstract}
RESUMO - (Atividade antimicrobiana de derivados fenólicos do líquen Ramalina sorediosa (B. de Lesd.) Laundron). A atividade antimicrobiana de extratos brutos de Ramalina sorediosa foi detectada pelo método de difusão em disco de papel. Dois metabólitos liquênicos de natureza fenólica foram identificados por meio de técnicas biocromatográficas. Uma dessas substâncias foi identificada por meio de cromatografia em camada delgada como sendo o ácido úsnico. A segunda substância, que se encontra presente em maior concentração em relação aos demais constituintes nos extratos, trata-se do ácido homossequicáico. As análises em cromatografia em camada delgada (CCD) e cromatografia líquida de alta eficiência (CLAE) revelaram ainda a presença do ácido salazínico. Os dados obtidos tornam possível atribuir a atividade antibiótica observada nesta espécie a uma provável associação sinérgica destas substâncias.
\end{abstract}

Palavras-chave: atividade antibiótica, Ramalina sorediosa, ácido homossequicáico

\begin{abstract}
Antimicrobian activity of phenols actives from the liquen Ramalina sorediosa (B. de Lesd.) Laundron). The antimicrobian activity of crude extracts from Ramalina sorediosa was detected by the diffusion disc-paper method. Two phenolic compounds from the lichen considered active were detected by using biochromathograhyc technique. Two of those compounds were identified through thin layer chromatographic technique (TLC) as been usnic acid and the second one, wich is present in higher concentration when compared with the other substances, was the homosekikaik acid. The TLC and high-pressure liquid chromatography (HPLC) assays still detected the salazanic acid presence. The obtained data make it possible to attribute the antibiotic activity of this species to a synergic association of those two substances.
\end{abstract}

Key words: antibiotic activity, Ramalina sorediosa, homosekikaik acid

\section{Introdução}

Os liquens produzem metabólitos resultantes de rotas secundárias, denominados substâncias liquênicas, também conhecidas como ácidos liquênicos. Atualmente, sabe-se que se tratam de derivados fenólicos e carboidratos exclusivos, sendo que estes metabólitos são os principais responsáveis por grande parte de sua bioatividade (Llano 1951; Vicente 1975; Xavier-Filho \& Rizzini 1976; Hale 1983). A origem biossintética das substâncias liquênicas ocorre em quatro vias: via do acetato-polimalonato, onde são sintetizadas a maioria das substâncias típicas, como quinonas, depsídeos, depsidonas e ácidos graxos; via do ácido mevalônico, onde ocorre a formação dos terpenóides e esteróis; via do ácido chiquímico, que origina muitos dos pigmentos amarelos; (Shibata 1964; Huneck 1973; Hale 1983). Além disso, Xavier-Fillho (1989) acrescenta mais uma via: a dos carboidratos, onde se têm os sacarídeos e polióis, produtos da redução de açúcares.

A atividade antibacteriana de liquens, ou de suas substâncias isoladas, tem sido estudada há muitos anos. Os primeiros estudos foram realizados por Burkholder et al. (1944). Posteriormente, muitos outros pesquisadores obtiveram resultados interessantes. Por exemplo, foi verificado que extratos brutos de várias espécies liquênicas eram ativos contra bactérias gram-positivas e álcool-ácido-resistentes como o bacilo da tuberculose (Mycobacterium tuberculosis var. bovis e M. tuberculosis var. hominis) (Bustinza 1951; Capriotti 1961; Silva et al. 1986; Xavier-Filho \& Rizzini 1976).

\footnotetext{
1 Parte de Dissertação de Mestrado do primeiro Autor

2 Departamentos de Bioquímica e Antibióticos, Universidade Federal de Pernambuco, Recife, PE, Brasil

3 Centro de Ciências Biológicas, Departamento de Ciências Geográficas, Centro de Filosofia e Ciências Humanas, Universidade Federal de Pernambuco, Av. Prof Moraes Rego, s/n, Cidade Universitária, CEP 50670-901, Recife, PE, Brasil

4 Autor para correspondência: arruda@hotlink.com.br
} 
Via de regra, as substâncias liquênicas são pouco eficientes contra bactérias gram-negativas e eficientes contra as gram-positivas (Hale 1983), inibindo seu crescimento. O ácido úsnico, isolado de Ramalina reticulata inibiu o crescimento de várias espécies de Pneumococcus, Staphylococcus e Streptococcus, além de Mycobacterium tuberculosis var. avium, e outras espécies de Mycobacterium patogênicas ao homem (Xavier-Filho \& Rizzini 1976; Marshak 1947; Marshak et al. 1947; Barry et al. 1947; Bustinza 1951). Lauterwein et al. (1995) demonstraram que metabólitos secundários de diferentes espécies de liquens eram inativos contra bactérias gram-negativas e fungos, entretanto possuíam atividade inibitória contra Staphylococcus aureus, Enterococcus faecalis, E. faecium e algumas espécies anaeróbicas como Bacteroides e Clostridium. Esses autores demonstraram ainda, que a susceptibilidade ao ácido úsnico se mantinha, mesmo em isolados clínicos de $S$. aureus. Ainda em relação a esta substância, Ingólfsdóttir et al. (1998) e Muller (2001) a consideraram de menor ação, quando comparada à rifampicina e estreptomicina.

Mais recentemente, Falcão et al. (2002) detectaram atividade antimicrobiana em extratos de Heterodermia leucomela, atribuindo tal efeito à presença de atranorina nos extratos da citada espécie. Os pesquisadores também relataram ação frente as bactérias gram-positivas. Ribeiro et al. (2002) testaram, além da referida atranorina, a leprolomina e os ácidos divaricático, girofórico, rocélico e salazínico, através de ensaios de microdiluição. Os autores constataram que o ácido salazínico foi inativo contra todos os microrganismos testados, enquanto a atranorina e a leprolomina inibiram Bacillus subtillis e Staphylococcus aureus. O ácido divaricático agiu apenas contra $B$. subtillis e os girofórico e rocélico contra S. aureus.

Neste trabalho a atividade antibiótica de extratos orgânicos de Ramalina sorediosa foi detectada por meio de ensaios de difusão em disco de papel sendo os componentes ativos identificados por meio de técnicas de cromatografia em camada delgada (CCD), Cromatografia líquida de alta eficiência (CLAE) e ensaios biocromatográficos.

\section{Material e métodos}

Coleta do material liquênico - Amostras de Ramalina sorediosa (B. de Lesd.) Laudron, foram coletadas em Alagoinha, região semi-árida de Pernambuco (caatinga). O material liquênico foi identificado mediante observação de características morfológicas e químicas do talo pelo Dr. Marcelo Marcelli do Instituto de Botânica de São Paulo. Sua exsicata foi depositada no herbário UFP sob registro número 36.432

Preparação dos Extratos - Os extratos foram obtidos por maceração do talo liquênico e agitação pelo método de esgotamento a frio, seguindo-se a série eluotrópica, a partir dos solventes, éter etílico, clorofórmio e acetona, em grau de pureza analítica, (Santos et al. 1997). Os extratos orgânicos foram evaporados em temperatura ambiente $\left(28 \pm 3^{\circ} \mathrm{C}\right)$ e mantidos em dessecador, até a realização dos testes de atividade antimicrobiana.

Atividade antimicrobiana - Os ensaios de atividade antibacteriana foram realizados em duplicata pelo método de difusão em disco de papel, em placas de Petri contendo meio de Müeller-Hinton, segundo metodologia descrita por Grove \& Randal (1955). O inóculo foi preparado segundo a metodologia de Bauer et al. (1966).

Foram selecionados para os ensaios os microrganismos Staphylococcus aureus (DAUFPE01), Bacillus subtilis (DAUFPE-16), Streptococcus faecalis (DAUFPE-138), como bactérias grampositivas; Pseudomonas aeruginosa (DAUFPE-39), Klebsiella pneumoniae (DAUFPE-396), Escherichia coli (DAUFPE-224), como bactérias gram-negativas; Mycobacterium smegmatis (DAUFPE-71), bactéria álcool-ácido-resistente; e amostras de Streptococcus $\beta$-hemolyticcus dos grupos sorológicos B e C (bactérias gram-positivas) isolados clínicos identificados e cedidos pelo laboratório de Análises Clínicas, Setor de Microbiologia, do Hospital das Clínicas da UFPE. Foram ainda utilizadas cinco espécies de fungos filamentosos (dermatófitos), Microsporon canis, M. gypsium, Epidermophyton floccosum, Trichophyton tonsurans, T. rubrum, isolados clínicos cedidos pelo Departamento de Micologia da UFPE, e duas espécies de fungos leveduriformes do gênero Candida, sendo quatro cepas de C. parapsilosis (URM-3624, 3626, 3621 e 3627) e seis de C. albicans (DAUFPE-1007, 4741 e URM 3620, 3622, 3629, 3628). O meio foi inoculado com suspensões de $10^{7} \mathrm{UFC}$. $\mathrm{mL}^{-1}$ de microrganismos.

Os discos foram impregnados com $50 \mu \mathrm{L}^{-1}$ de soluções a 2,0mg.mL ${ }^{-1}$ de cada extrato orgânico e então incubados a $37^{\circ} \mathrm{C}$ por $24 \mathrm{~h}$. Discos previamente umedecidos com os solventes orgânicos foram utilizados como controle negativo, enquanto discos impregnados com $50 \mu \mathrm{L}^{-1}$ de soluções a 2,0 mg.mL ${ }^{-1}$ dos ácidos úsnico, difractáico e atranorina foram 
utilizados como controle positivo.

Os resultados foram analisados através da mensuração dos halos de inibição ao redor dos discos, sendo expressos em milímetros (mm).

Análise dos fenóis liquênicos - A análise da fração fenólica foi realizada por meio de técnicas de cromatografia em camada delgada (CCD) e cromatografia líquida de alta eficiência (CLAE).

Os ensaios de CCD foram realizados em placas de gel de sílica $\mathrm{F}_{254+366}$. Merck. A fase móvel utilizada era constituída de toluenoldioxanolácido acético (180:45:5 v/v), de acordo com a metodologia de Culberson (1972).

As manchas foram visualizadas por fluorescência em luz UV (254 e 366nm) e reveladas com ácido sulfúrico a $10 \%$ e aquecimento a $100^{\circ} \mathrm{C}$, sendo identificadas através de comparação de seus Rfs com aqueles obtidos para as substâncias padrão: ácidos salazínico, úsnico, homossequicáico e norstítico. Os padrões de ácido salazínico e úsnico utilizados foram subtâncias puras, enquanto que os ácidos homolsequicaico e norstítico, foram obtidos de Cladonia signata e Cladonia symphycarpa (Ach.) Fr., espécies coletadas na Finlândia e gentilmente cedidas e identificadas por T. Ahti e S. Stenros (University of Helsinki).

Os extratos orgânicos (etéreo, clorofórmico e acetônico) foram diluídos em seus respectivos solventes até uma concentração de $2,0 \mathrm{mg} \cdot \mathrm{mL}^{-1}$, sendo aplicados à placa $50 \mu \mathrm{L}$ das respectivas soluções e padrões.

Os ensaios em CLAE foram realizados em cromatógrafo HITACHI modelo 655A-11, acoplado a um detector de UV CG, modelo CG437-B. As condições de cromatografia foram, segundo Legaz \& Vicente (1983): coluna de fase reversa MicroPack MCH-18 de $300 \times 4 \mathrm{~mm}$ com volume de $20 \mu \mathrm{L}$; fase móvel isocrática constituída por (metanol : água : ácido acético 80:19,5:0,5 v/v); pressão de 88 atm e temperatura ambiente de $30^{\circ} \mathrm{C}$; detector de $\mathrm{UV}$ regulado a $254 \mathrm{~nm}$; padrões internos de $0,1 \mathrm{mg} \cdot \mathrm{mL}^{-1}$ de atranorina, ácidos úsnico, e salazínico. Os extratos foram diluídos até a concentração de $0,1 \mathrm{mg} \cdot \mathrm{mL}^{-1} \mathrm{e}$ então injetados no aparelho. Os resultados foram avaliados mediante a determinação do tempo de retenção (TR) das substâncias na coluna e a área dos picos, respectivamente.

Identificação dos componentes ativos através de biocromatografia - A biocromatografia foi realizada por meio da metodologia de Homans e Fuchs (1970), modificada por L.O. Costa-Filho (dados não publicados). Os extratos ativos nos ensaios de atividade antibacteriana, à concentração de 2,0mg.mL, foram aplicados em placas de gel de sílica F-254nm Merck $(5 \times 10 \mathrm{~cm})$, segundo a metodologia utilizada para a análise em CCD. As placas foram armazenadas até a completa evaporação dos solventes.

O inóculo foi preparado da mesma forma que os ensaios de atividade antimicrobiana. Os cromatogramas foram colocados dentro de placas-de-Petri $(18 \mathrm{~mm})$, recebendo então uma fina camada de meio (50mL) pré-inoculado com os microrganismos teste $(100 \mu \mathrm{L})$. As substâncias separadas que apresentaram atividade antibacteriana foram detectadas através da visualização de halos de inibição ao seu redor.

Foram utilizados como microrganismos teste Staphylococcus aureus (DAUFPE-01) e o Bacillus subtilis (DAUFPE-16); os extratos avaliados foram o clorofórmico e etéreo e o ácido norstítico como padrão.

\section{Resultados e discussão}

Atividade Antimicrobiana - Os ensaios foram realizados em duplicata, sendo os resultados apresentados com os respectivos desvios padrão, que se mostraram não significantes.

Os extratos orgânicos mostraram-se inativos frente a todas as bactérias gram-negativas, fungos e os dois Streptococcus $\beta$-hemolyticcus (Tab. 1). Apenas os extratos etéreo e clorofórmico exibiram atividade antibacteriana contra os microrganismos utilizados.

Ao contrário o extrato acetônico não apresentou qualquer atividade inibitória. Estes resultados estão de acordo com Hale (1983) que verificou a baixa eficiência de substâncias liquênicas contra bactérias gram-

Tabela 1. Atividade antimicrobiana dos extratos orgânicos de Ramalina sorediosa (B. de Lesd.).

Microorganismos/Zona de inibição (mm)

\begin{tabular}{lcc}
\hline Tratamento & $\begin{array}{c}\text { Bacillus subtilis } \\
\text { DAUFPE-16 } \\
\mathrm{X} \pm \mathrm{Dp}\end{array}$ & $\begin{array}{c}\text { Staphylococcus aureus } \\
\text { DAUFPE-01 }\end{array}$ \\
& $\mathrm{X} \pm \mathrm{Dp}$ \\
Extrato Etéreo & $16,7 \pm 0,5$ & $14,7 \pm 0,5$ \\
Extrato Clorofórmico & $16,7 \pm 0,5$ & $13,6 \pm 0,5$ \\
Extrato Acetônico & $0,0 \pm 0,0$ & $0,0 \pm 0,0$ \\
Ácido úsnico & $19,6 \pm 0,5$ & $11,7 \pm 0,5$ \\
Atranorina & $19,3 \pm 0,5$ & $8,0 \pm 0,0$ \\
Ácido difractáico & $9,3 \pm 0,5$ & $7,7 \pm 0,5$ \\
\hline
\end{tabular}

$\mathrm{N}$ amostral $=2$; Desvio Padrão $=\mathrm{Dp}$; Média $=\mathrm{X}$ 
negativas, e com Bustinza(1951), Capriotti (1961), Silva et al. (1986) e Xavier-Filho \& Rizzini (1976), que citaram a atividade de várias espécies liquênicas contra bactérias gram-positivas e ácido-álcool-resistentes. Na Tab. 1 são apresentados os dados de atividade inibitória dos extratos orgânicos testados apenas contra os microrganismos que se mostraram sensíveis. Nela verifica-se que os extratos etéreo e clorofórmico foram ativos, apresentando atividades semelhantes.

Análise do Fenóis Liquênicos - A análise em CLAE do extrato etéreo de $R$. sorediosa, revelou oito sinais, três com maiores concentrações, com tempos de retenção de 4,84min; 8,72min e 14,27min, além de dois menores com TR de 3,68min e 9,74 min (Fig. 1A). Destes o que apresentou a maior concentração foi o de $\mathrm{TR}=14,27$ min com 55,27\% da concentração do extrato (Tab. 2). Este sinal, provavelmente, devido à sua concentração, deve corresponder à mancha de $\mathrm{Rf}=0,68$, que foi observada nos ensaios em CCD dos extratos etéreo e clorofórmico da referida espécie liquênica (Fig. 2). Um dos sinais encontrados tem $\mathrm{TR}=3,68 \mathrm{~min}$, semelhante ao encontrado para o padrão do ácido salazínico (TR=3,47min) (Fig. 1 D).

A análise em CLAE do extrato clorofórmico de $R$. sorediosa (Fig. 1B) mostrou também oito sinais, sendo três com concentrações maiores e tempos de retenção de 3,70min; 4,92min e 14,98 min, e dois menores com tempos de retenção de 9,05min e $10,14 \mathrm{~min}$. Os sinais que apresentaram maior concentração foram os de TR iguais a 4,92min e 14,98 min com 20,50\% e 42,28\% do extrato (Tab. 2).
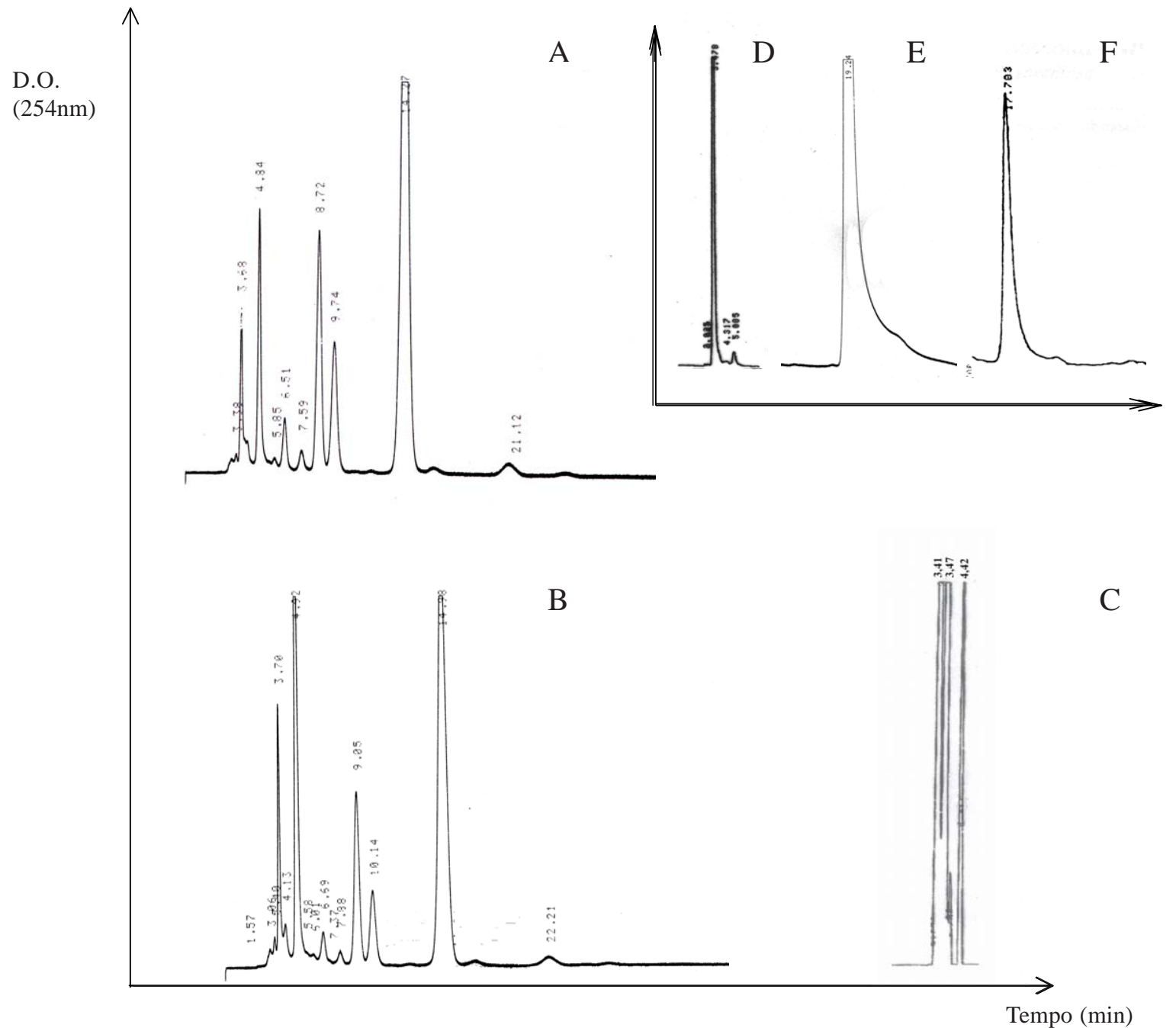

Figura 1. Cromatogramas em CLAE dos extratos etéreo (A), Clorofórmico (B) e Acetônico (C) de Ramalina sorediosa (B. de Lesd.) e dos padrões de ácido salazínico (D), úsnico (E) e atranorina (F). D.O. - Densidade Ótica. 
Tabela 2. Concentração dos principais componentes do extrato etéreo de Ramalina sorediosa (B. de Lesd.).

\begin{tabular}{lcccc}
\hline Padrões & $\begin{array}{c}\text { Tempo de } \\
\text { retenção (min.) }\end{array}$ & $\begin{array}{c}\text { Substância } \\
\text { correspondente }\end{array}$ & $\begin{array}{c}\text { Conc. } \\
(\%)\end{array}$ & $\mu \mathrm{g} / \mathrm{mg}$ \\
& 3,68 & SAL & 5,90 & 59,0 \\
& 4,84 & & 9,28 & 92,80 \\
& 8,72 & & 13,64 & 136,40 \\
& 9,74 & & 9,17 & 91,70 \\
& 14,27 & & 55,27 & 552,70 \\
USN & 21,12 & USN & 1,90 & 19,0 \\
ATR & 19,24 & & 100 & 1000 \\
SAL & 17,70 & & 100 & 1000 \\
& 3,47 & & 100 & 1000 \\
\hline
\end{tabular}

O gênero Ramalina, no Brasil, foi estudado por Kashiwadani \& Kalb (1993). Estes pesquisadores citaram para $R$. sorediosa a presença de quatro componentes principais, que são os ácidos salazínico, sequicaico, homossequicáico e úsnico.

Os ensaios cromatográficos em CCD demonstraram a presença de ácido úsnico, em pequena quantidade nos extratos etéreo e clorofórmico (Fig. 2) de $R$. sorediosa. Os cromatogramas em CLAE demonstraram a presença de um sinal arredondado com TR semelhante ao do ácido úsnico $(21,12 \mathrm{~min}$.) conforme demonstra a Fig. 1A. Portanto, provavelmente esta substância é co-responsável pela atividade antimicrobiana visualizada, agindo isoladamente, ou sinergicamente com outras substâncias presentes no extrato.

A análise em CLAE do extrato acetônico de $R$. sorediosa mostrou três sinais (Fig. 1C), todos com concentrações elevadas e tempos de retenção de 3,02min.; 3,47min. e 4,42min. Quando somados, estes representam 94,73\% do extrato bruto (Tab. 3). Dos sinais principais a substância com maior concentração (62,29\%), apresenta um TR correspondente ao do padrão de ácido salazínico (TR = 3,47min.) (Fig. 1D), confirmando os resultados observados em CCD (Fig. 2). Esta depsidona do grupo orcinol foi testada por Shibata \& Miura (1948), sendo considerada pouco ativa frente ao $B$. subtilis, quando comparada a outras substâncias liquênicas. É importante lembrar que aqueles pesquisadores utilizaram o ácido puro, em contraste com o extrato orgânico utilizado para os testes de atividade antibacteriana neste trabalho. Por outro lado, a falta de atividade do extrato acetônico abre a perspectiva para investigação complementar no sentido de averiguar se o fato ocorre em função da baixa concentração do princípio ativo no extrato, ou se
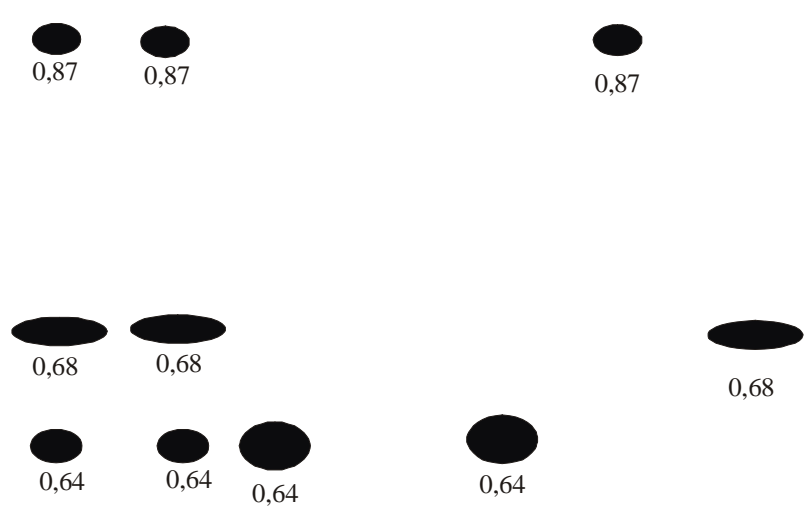

Figura 2. Modelo Esquemático do Cromatograma em camada delgada dos extratos orgânicos de Ramalina sorediosa (B. de Lesd.). Et Rs - Extrato etéreo de R. sorediosa; Cl Rs - Extrato clorofórmico; Ac Rs - Extrato acetônico; SAL - Ácido salazínico; NST - Ácido norstítico; USN - Ácido úsnico; HSEK - Ácido Homossequicáico.

o solvente não é adequado para a extração do mesmo, ou, em outra hipótese, um antagonismo entre as substâncias presentes no citado extrato.

A composição química dos extratos etéreo e clorofórmico diferem daquela observada para o extrato acetônico, sendo constante apenas o ácido norstítico que apresentou concentrações maiores neste último extrato (Fig. 2). Embora não tenham sido encontradas citações na literatura relacionando esta substância à espécie liquênica em estudo, esta mesma substância já foi encontrada em espécies congêneres no Peru (Kashiwadani 1987) e Chile (Kashiwadani 1990). Além disto, estudos em CLAE, de fenóis liquênicos, conduzidos por Huneck e Yoshimura (1996), mostram que o ácido norstítico apresenta um tempo de retenção maior que o ácido salazínico, sendo eluído primeiro, em condições experimentais semelhantes deste trabalho. 
Tabela 3. Concentração dos principais componentes do extrato clorofórmico de Ramalina sorediosa (B. de Lesd.).

\begin{tabular}{lcccc}
\hline Padrões & $\begin{array}{c}\text { Tempo de } \\
\text { retenção (min.) }\end{array}$ & $\begin{array}{c}\text { Substância } \\
\text { correspondente }\end{array}$ & $\begin{array}{c}\text { Conc. } \\
(\%)\end{array}$ & $\mu \mathrm{g} / \mathrm{mg}$ \\
& 3,70 & SAL & 2,08 & 20,80 \\
& 4,92 & & 20,50 & 205,0 \\
& 9,05 & & 11,15 & 111,50 \\
& 10,14 & & 5,70 & 57,0 \\
& 14,98 & & 42,28 & 422,80 \\
USN & 22,21 & USN & 1,60 & 16,00 \\
ATR & 19,24 & & 100 & 1000 \\
SAL & 17,70 & & 100 & 1000 \\
& 3,47 & & 100 & 1000 \\
\hline
\end{tabular}

Deste modo pode-se afirmar que as substâncias encontradas neste último extrato são inativas. Portanto, a atividade observada deve-se, provavelmente, à presença das substâncias de Rf 0,68 e 0,87 , que correspondem aos ácidos homossequicáico e úsnico, não encontrados no extrato acetônico, sendo a maior atividade antimicrobiana demonstrada pelo extrato etéreo (Fig. 1A). Provavelmente isto se deve à maior capacidade deste solvente em extrair substâncias pouco polares, como o ácido úsnico, que possivelmente encontra-se em concentração ligeiramente maior que no extrato clorofórmico.

Os resultados obtidos com os dois primeiros extratos poderiam sugerir que o ácido norstítico, presente nos extratos etéreo e clorofórmico, fosse um dos responsáveis pela atividade antibacteriana, no entanto esta substância, juntamente com o ácido salazínico estão presentes em altas concentrações no extrato acetônico, que foi inativo. As análises em CCD revelaram a presença de duas substâncias majoritárias uma com $\mathrm{Rf}=0,68$ e outra com $\mathrm{Rf}=0,87$ (Fig. 2). A substância com $\mathrm{Rf}=0,87$ foi identificada, por comparação com os padrões como sendo o ácido úsnico. Desde que a concentração do suposto ácido

Tabela 4. Concentração dos principais componentes do extrato acetônico de Ramalina sorediosa (B. de Lesd.).

\begin{tabular}{lcccc}
\hline Padrões & $\begin{array}{c}\text { Tempo de } \\
\text { retenção (min.) }\end{array}$ & $\begin{array}{c}\text { Substância } \\
\text { correspondente }\end{array}$ & $\begin{array}{c}\text { Conc. } \\
(\%)\end{array}$ & $\mu \mathrm{g} / \mathrm{mg}$ \\
& 3,02 & & 16,17 & 161,70 \\
& 3,47 & SAL & 62,29 & 622,90 \\
USN & 4,42 & & 16,27 & 162,70 \\
ATR & 19,24 & & 100 & 1000 \\
SAL & 17,70 & & 100 & 1000 \\
& 3,47 & & 100 & 1000 \\
\hline
\end{tabular}
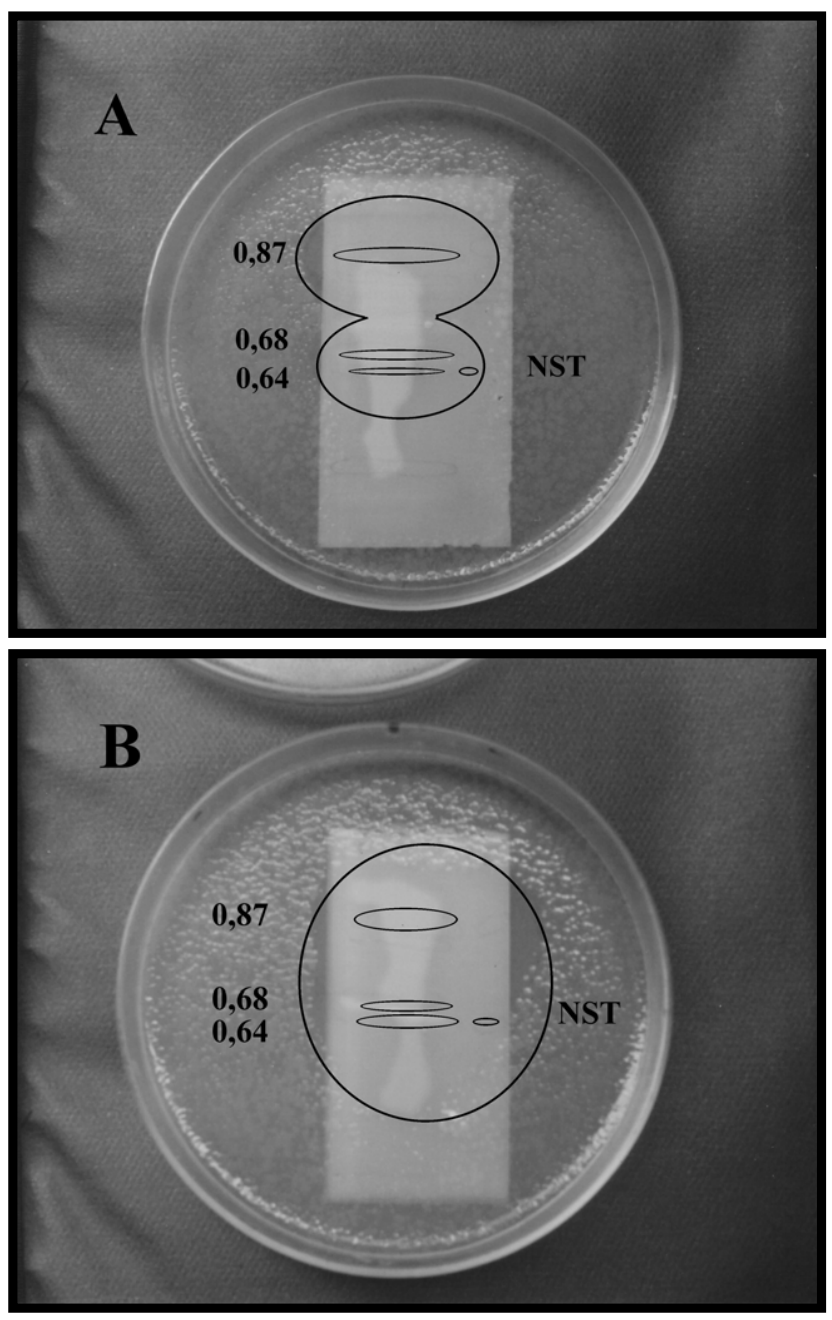

Figura 3. Biocromatogramas dos extratos Clorofórmico (A) e Etéreo (B) de Ramalina sorediosa (B. de Lesd.) contra Bacillus subtilis e representação do halo de inibição sobre as manchas cromatográficas (Rf = 0,87; 0,68; 0,64) e o Ácido Norstítico (NST).

úsnico, nos extratos orgânicos, é relativamente baixa e a atividade antibacteriana é muito próxima àquela observada para o padrão mais ativo, o ácido úsnico puro (Tab. 1), a atividade observada é, provavelmente, devida a uma ação sinérgica dos dois constituintes (Rf 0,68 e Rf 0,87).

Biocromatogramas - Com relação aos biocromatogramas observou-se um provável efeito sinérgico entre componentes dos extratos etéreo e clorofórmico de Ramalina sorediosa (Fig. 3A e 3B) quando testados contra o Bacillus subtilis, sendo observados halos de inibição sobre todas as manchas. Pode-se observar um halo de inibição muito maior no caso do extrato etéreo de $R$. sorediosa em relação ao clorofórmico, para a referida espécie, o que já era previsto devido à sua maior atividade observada nos testes de atividade antibacteriana (Tab. 1). 
Os resultados mostraram que os componentes ativos nos extratos de $R$. sorediosa correspondem as manchas de Rf 0,68 e 0,87. Os ensaios biocromatográficos e de CLAE demonstram que correspondem aos ácidos homossequicáico e úsnico, respectivamente. Por outro lado, verificou-se a inatividade do extrato acetônico e, inclusive o ácido salazínico nele detectado. Além disto, os ensaios biocromatográficos mostram que provavelmente deve haver ação sinérgica entre os componentes ativos nos extratos, contra os microrganismos testados.

\section{Agradecimentos}

Os autores agradecem ao Dr. Marcelo Marcelli, pela identificação da espécie; ao apoio financeiro do Conselho Nacional de Pesquisa (CNPq) e pelo suporte técnico do Laboratório de Imunopatologia Keizo Asami (LIKA). Um dos autores (E.C. Pereira) é bolsista de Produtividade em Pesquisa (CNPq).

\section{Referências bibliográficas}

Burkholder, P.R.; Evans, A.W.; Macveigh, I. \& Thorton, H.R. 1944. Antibiotic activity of lichens. Proceedings of the National Academy of Sciences of Washington 30(9): 250-255.

Bauer, A.W.; Kirby, W.M.M.; Sherris, J.C. \& Truck, M. 1966. Antibiotic Susceptibility Testing by a Standardized Single Disk Method. The American Journal of Clinical Pathology 45(4): 493-496.

Barry, V.C.; O’Rourke, L. \& Twomey, D. 1947. Antitubercular activity of diphenil ether and related compounds. Nature 160: 800.

Bustinza, F. 1951. Contribuicion al estudio de las propriedades antibacterianas y antifungicas del acido usnico y algunos de sus derivados. Annales del Instituto Botanico A.J. Cavanilles 10: 157-175.

Capriotti, A. 1961. The effect of Usno on Yeast isolated from the excretion of tuberculosis patients. Antibiotic and Chemotherapy 11(6): 409-410.

Culberson, C.F. 1972. Improved conditions and new data for the identification of lichen products by standardized thin layer-cromatografic method. Journal of Chromatography 72: 113-125.

Falcão, E.P.S.; Silva, N.H.; Pereira, E.C.; Gusmão, N.B. \& Ribeiro, S.M. 2002. Atividade antimicrobiana de Compostos Fenólicos do Líquen Heterodermia leucomela (L.) Poelt. Acta Farmaceutica Bonarense 21(1): 43-49

Grove, D.C. \& Randal, W.A. 1955. Assay Methods, Antibiotic Activity:A laboratory Manual. New York, Medical Enciclopedia.
Hale Jr., M.E. 1983. The Biology of lichens. 3 ed. London Edward Arnold Pub.

Homans, A.L. \& Fuchs, A. 1970. Direct bioautography on thin layer, Cromatograms as method for detecting fungitoxic substances. Journal of Cromatography 51: 327-329.

Huneck, S. 1973. Nature of Lichens Substances. V. Ahmajadajin \& M.E. Hale. The Lichens. London, Academic Press.

Ingolfsdottir, K.; Chung, G.A.C.; Skulason, V.G.; Gissurason, S.R. \& Vilhelmsdottir, M. 1998. Antimycobacterial activity of lichen metabolites in vitro. European Journal of Pharmaceutical Sciences 6: 141-144.

Huneck, S. \&Yoshimura, I. 1996. Identification of lichen substances. Springer Verlag, Berlin.

Kashiwadani, H. 1987. Peruvian Species of Ramalina (Lichens) Reprinted from: H. Inoue (ed.). Studies on Criptogams in Southern Peru. p. 1992 Tokio, Tokai University Press.

Kashiwadani, H. 1990. Some Chilean Species of the Genus Ramalina (Lichens), Tokio. Bulletin of the National Science Museum, Ser. B 16(1):1-12.

Kashiwadani, H. \& Kalb, K. 1993.The genus Ramalina in Brazil, The Lichenologist 25(1): 1-1.

Lauterwein, M.; Oethinger, M.; Belsner, K.; Peters, T. \& Marre, R. 1995. In vitro activities of lichen secondary metabolites vulpinic acid (+)-úsnic acid, and (-)-úsnic acid against aerobic and anaerobic microorganisms. Antimicrobial Agents and Chemotherapy 2541-2543.

Llano, G.A. 1951. Economic Use of Lichens. Smithsonian Institute Publ. 4040: 385-422.

Legaz, M.E.E. \& Vicente, C. 1983. Endogenous inactivators of arginase, arginine decarboxilase and agmnatine amidinohydrolase in Evernia prusnatri thallus. Plant Physiologie 71: 300-302.

Marshak, A. 1947. A cristaline antibacterial substance from the lichen Ramalina reticulata. Public Health Reports 62: 3-19.

Marshak, A.; Barry, G.T. \& Graig, L.G. 1947. Antibiotic compound isolated from the lichen Ramalina reticulata. Science 106: 394-395.

Muller, R. 2001. Pharmaceutically relevant metabolites from lichens. Applied Microbiology and Biotecnology 56: 9-16.

Ribeiro, S.M.; Pereira, E.C.; Nicácio, S.; Falcão, E.P.; Gusmão, N.B.; Honda, N. \& Quilhot, W. 2002. Mitteinlunger aus dem Institute für Allgemeline Botanic Hamburg 3032: 187-194.

Santos, P.N.; Pereira, E.C.G.; Lima, R.C.; Honda, K.N.; Silva, M.P.C. \& Silva, N.H. 1997. Efeito da sazonalidade na produção de metabólitos com ação antitumoral em Cladonia verticillaris (Líquen). Revista da Universidade do Amazonas, Série Ciências Biológicas, Manaus, v.2, n.2.

Shibata, S. 1964. Biogenetical and chemotaxonomical aspects of lichen substances. In: Beitrage zur Biochemie und Physiologie von Naturstoffen 30: 451-465.

Shibata, S. \& Miura, Y. 1948. Antibacterial effects of lichen substances. II - Studies on didimic acid and related compounds. Japan Medical Journal of Sciences in Bology 2: 22-24. 
Silva, J.O.; Leite, J.E.M.; Paulo, M.Q. \& Xavier-Filho, L. 1986. Atividade antimicrobiana de liquens brasileiros I.

Boletim da Sociedade Broteriana 59(2): 87-96.

Vicente, C. 1975. Fisiologia de las Substâncias Liquênicas. Madrid, Alhandra.
Xavier-Filho, L. \& Rizzini, C.T. 1976. Manual de Liquenologia Brasileiro. Recife, Universidade Federal de Pernambuco. Xavier-Filho, L. 1989. Inibição Fotooxidativa de b-Caroteno por Cloroatranorina de Parmelia tinctorum Nyl. João Pessoa: UFPB.Tese de Titular - Laboratório de Tecnologia Farmacêutica, UFPB. 